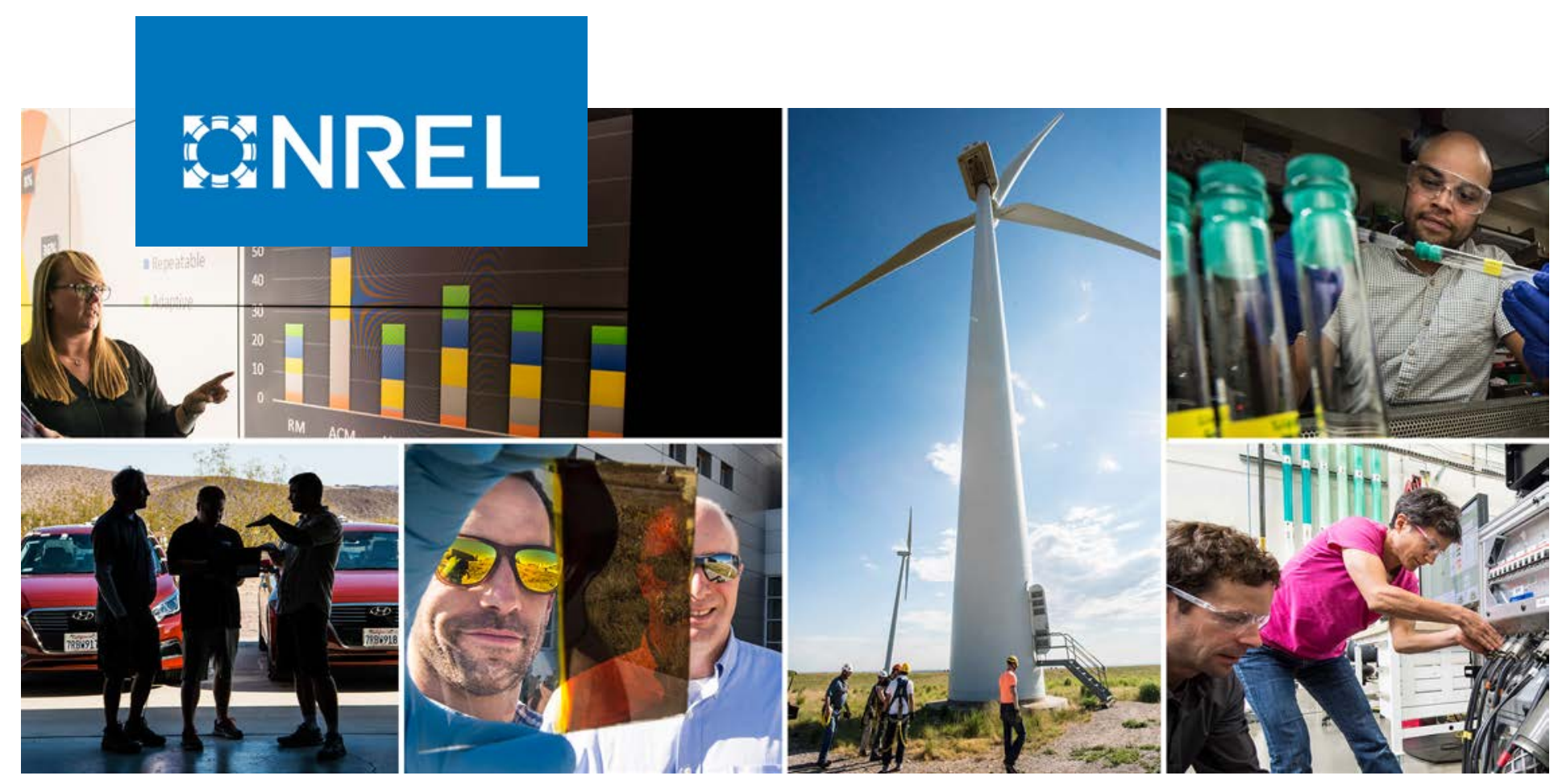

\title{
Report of the Condition of a General Electric Transportation Systems Gearbox
}

Jonathan Keller, ${ }^{1}$ Mark Michaud, ${ }^{2}$ and Scott Lambert ${ }^{1}$

\author{
1 National Renewable Energy Laboratory \\ 2 REM Surface Engineering
}

NREL is a national laboratory of the U.S. Department of Energy Office of Energy Efficiency \& Renewable Energy

Operated by the Alliance for Sustainable Energy, LLC

This report is available at no cost from the National Renewable Energy Laboratory (NREL) at www.nrel.gov/publications.
Technical Report

NREL/TP-5000-76004

Revised February 2022 


\section{GNREL}

\section{Report of the Condition of a General Electric Transportation Systems Gearbox}

Jonathan Keller, ${ }^{1}$ Mark Michaud, ${ }^{2}$ and Scott Lambert ${ }^{1}$

1 National Renewable Energy Laboratory

2 REM Surface Engineering

\section{Suggested Citation}

Keller, Jonathan, Mark Michaud, and Scott Lambert. 2020. Report of the Condition of a General Electric Transportation Systems Gearbox. Golden, CO: National Renewable Energy Laboratory. NREL/TP-5000-76004. nrel.gov./docs/fy20osti/76004.pdf.

NREL is a national laboratory of the U.S. Department of Energy Office of Energy Efficiency \& Renewable Energy Operated by the Alliance for Sustainable Energy, LLC

This report is available at no cost from the National Renewable Energy Laboratory (NREL) at www.nrel.gov/publications.

Contract No. DE-AC36-08GO28308
Technical Report NREL/TP-5000-76004 Revised February 2022

National Renewable Energy Laboratory 15013 Denver West Parkway Golden, CO 80401

303-275-3000 • www.nrel.gov 


\section{NOTICE}

This work was authored in part by the National Renewable Energy Laboratory, operated by Alliance for Sustainable Energy, LLC, for the U.S. Department of Energy (DOE) under Contract No. DE-AC36-08GO28308. Funding provided by the U.S. Department of Energy Office of Energy Efficiency and Renewable Energy Wind Energy Technologies Office. The views expressed herein do not necessarily represent the views of the DOE or the U.S. Government.

This report is available at no cost from the National Renewable Energy Laboratory (NREL) at www.nrel.gov/publications.

U.S. Department of Energy (DOE) reports produced after 1991 and a growing number of pre-1991 documents are available free via www.OSTI.gov.

Cover Photos by Dennis Schroeder: (clockwise, left to right) NREL 51934, NREL 45897, NREL 42160, NREL 45891, NREL 48097, NREL 46526.

NREL prints on paper that contains recycled content. 


\section{Errata}

This report, originally published in April 2020, has been revised in February 2022 to correct the unit of the density of the lubricant in Table 1 . Per reference 22 , the correct density is $870 \mathrm{~kg} / \mathrm{m}^{3}$, not $870 \mathrm{~kg} / \mathrm{mm}^{3}$. 


\section{Acknowledgments}

The authors would like to thank Curt Eliason of Renew Energy Maintenance, Darrin Oates of General Electric Renewable Energy, Robert Errichello of GearTech, and REM Surface Engineering for their contributions. 


\section{List of Acronyms}

DOE U.S. Department of Energy

GE

General Electric

GETS

$\mathrm{kNm}$

$\mu \mathrm{m}$

$\mathrm{mm}$

MW

MWh

General Electric Transportation Systems

kilonewton meter

microns

millimeter

megawatt

megawatt-hour

NREL

National Renewable Energy Laboratory

O\&M

operation and maintenance 


\section{Table of Contents}

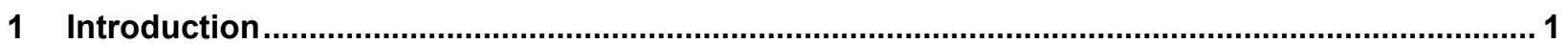

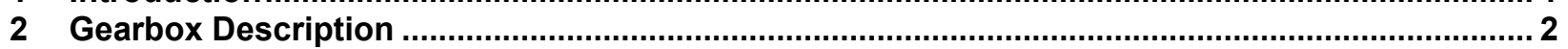

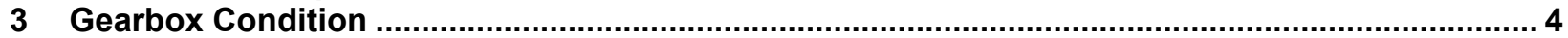

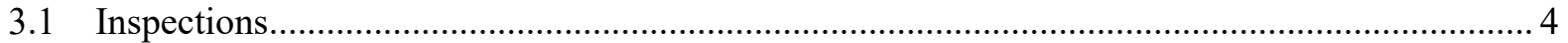

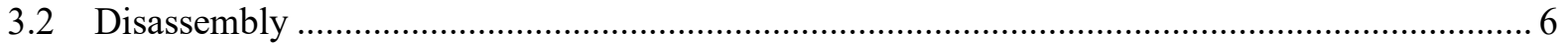

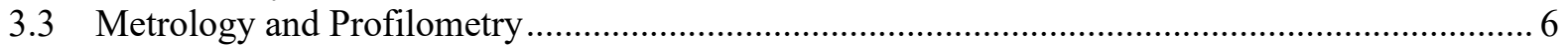

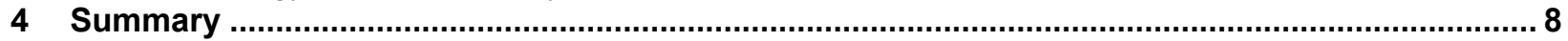

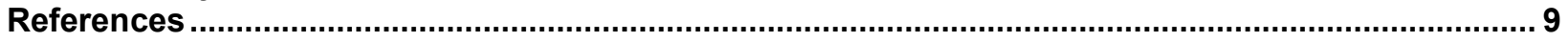

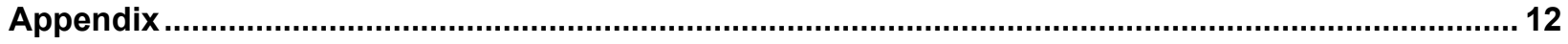




\section{List of Figures}

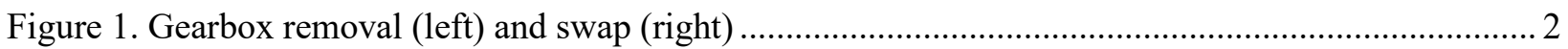

Figure 2. Schematic (left) and cutaway view (right) of the 7GA87 gearbox [21] ................................... 3

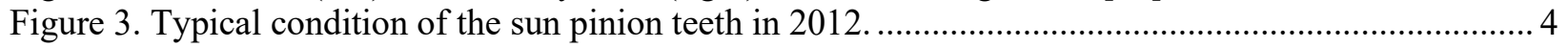

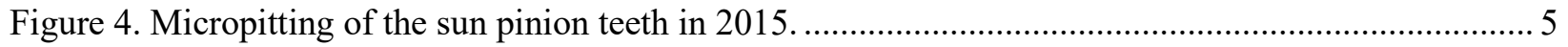

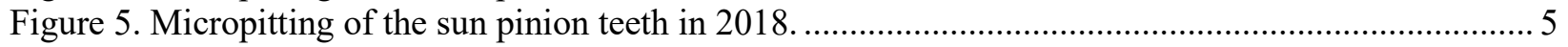

Figure 6. Gearbox disassembly (left) and sun pinion inspection (right) ............................................. 6

Figure 7. Sun pinion root micropitting (left) and localized corrosion spot with micropitting halo (right)... 7

Figure 8. Sun pinion before (left) and after (right) isotropic superfinishing........................................... 7

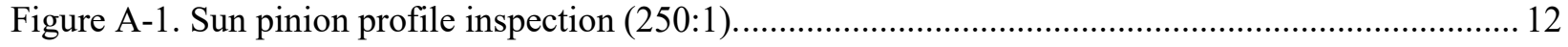

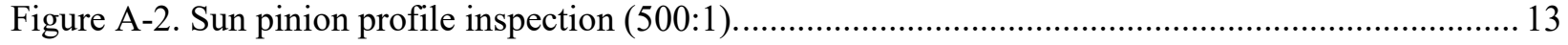

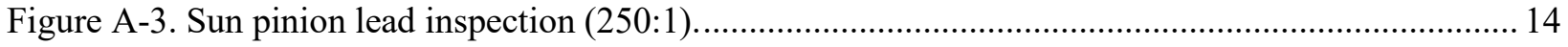

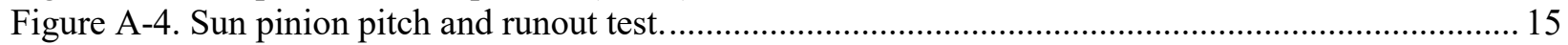

\section{List of Tables}

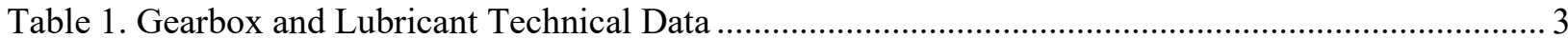




\section{Introduction}

Wind power plant operation and maintenance (O\&M) costs remain an appreciable contributor to the overall cost of wind energy, with a capacity-weighted average of $\$ 11 /$ megawatt-hour (MWh) for projects installed since 2000 and \$9/MWh for projects installed since 2010 [1]. These costs are higher than anticipated and at an unacceptable level to operators based on their current business models [2]. Wind turbine O\&M costs constitute less than half of total wind plant costs, including a significant percentage from premature gearbox failures [3]. These premature failures are often the result of abrasive wear, micropitting, scuffing, white-etch cracks, and macropitting issues $[2,4]$. Although damage to the gears occurs less frequently than damage to the bearings in wind turbine gearboxes [5], gear damage still presents a reliability challenge. In addition, gear damage that generates debris can contribute to bearing failure.

Micropitting is a fatigue phenomenon that occurs in hertzian contacts in both gears and rollingelement bearings that operate in mixed- or micro-elastohydrodynamic lubrication regimes, such as those wind turbine gearboxes typically operate in. Micropitting is influenced by, and manifests itself in, many different ways depending on operating conditions such as load, speed, and operating temperature, and on factors such as gear geometry and accuracy, tooth-flank roughness, percentage of tooth sliding, and lubricant composition [6,7]. It occurs on the asperity level. During cyclical loading, metal-to-metal asperity contacts result in microcracks propagating down into the tooth surface. The microcracks grow, turn upward, and eventually coalesce, resulting in a small particle detaching from the surface forming a micropit. Continued propagation of micropits causes a loss of material and degradation in gear tooth accuracy; in some cases, it can be the primary failure mode of the gear and gearbox. Despite much research by many investigators, micropitting remains complex, unpredictable, and difficult to control [8] and remains a problem in wind turbine gearboxes [9]. Recently, analytical methods have been proposed in ISO/TS 6336-22 that describe a micropitting safety factor for a given gear design [10]; however, these methods are not universally agreed upon and a method to calculate a percent of micropitting risk is still under development [11].

A multipronged research program supported by the U.S. Department of Energy (DOE) at Argonne National Laboratory and the National Renewable Energy Laboratory (NREL) is examining premature main bearing and gearbox failures, including such issues as gear-coupling rating [12], planetary load-sharing [13], bearing-axial cracking [14], and main bearing wear [15]. As early as 2009, micropitting in wind turbine gearboxes was of interest to industry and the research community [16]. Because of continued feedback from industry [17,18], a new effort has begun to examine gear-tooth micropitting. This report marks the beginning of this effort; its purpose is to document and describe the micropitting damage observed in a wind turbine gearbox, thereby facilitating further analysis and examination in future reports. 


\section{Gearbox Description}

The DOE began installing a General Electric (GE) 1.5-megawatt (MW) wind turbine at its National Wind Technology Center on NREL's Flatirons Campus in Colorado in late 2008; first operations began on May 15, 2009. This turbine, hereafter referred to as the DOE 1.5, is built on the platform of the GE 1.5 SLE commercial wind turbine model. A series of tests was previously conducted to characterize the baseline properties and performance of the DOE 1.5, including mechanical loads per International Electrotechnical Commission 61400-11, in March 2011 [19].

Since then, the DOE 1.5 was operated with the primary objective of supporting many DOE wind program and industry partner research initiatives. To enable a new research initiative for the investigation of bearing-axial-fatigue cracking in the gearbox and main bearing wear, the original drivetrain in the DOE 1.5 was swapped for a new, instrumented drivetrain on December 16, 2017 (Figure 1). The original drivetrain, consisting of a GE Transportation Services (GETS) gearbox, main shaft, and main bearing, had produced approximately 6-million kilowatt-hours $(\mathrm{kWh})$ of energy in 14.17-thousand hours of grid operation time [20]. Full operational data from this original GETS gearbox was retained and will be used in ongoing research and analyses. It should be noted that the above time period represents approximately $8 \%$ of the minimum design life of the gearbox.
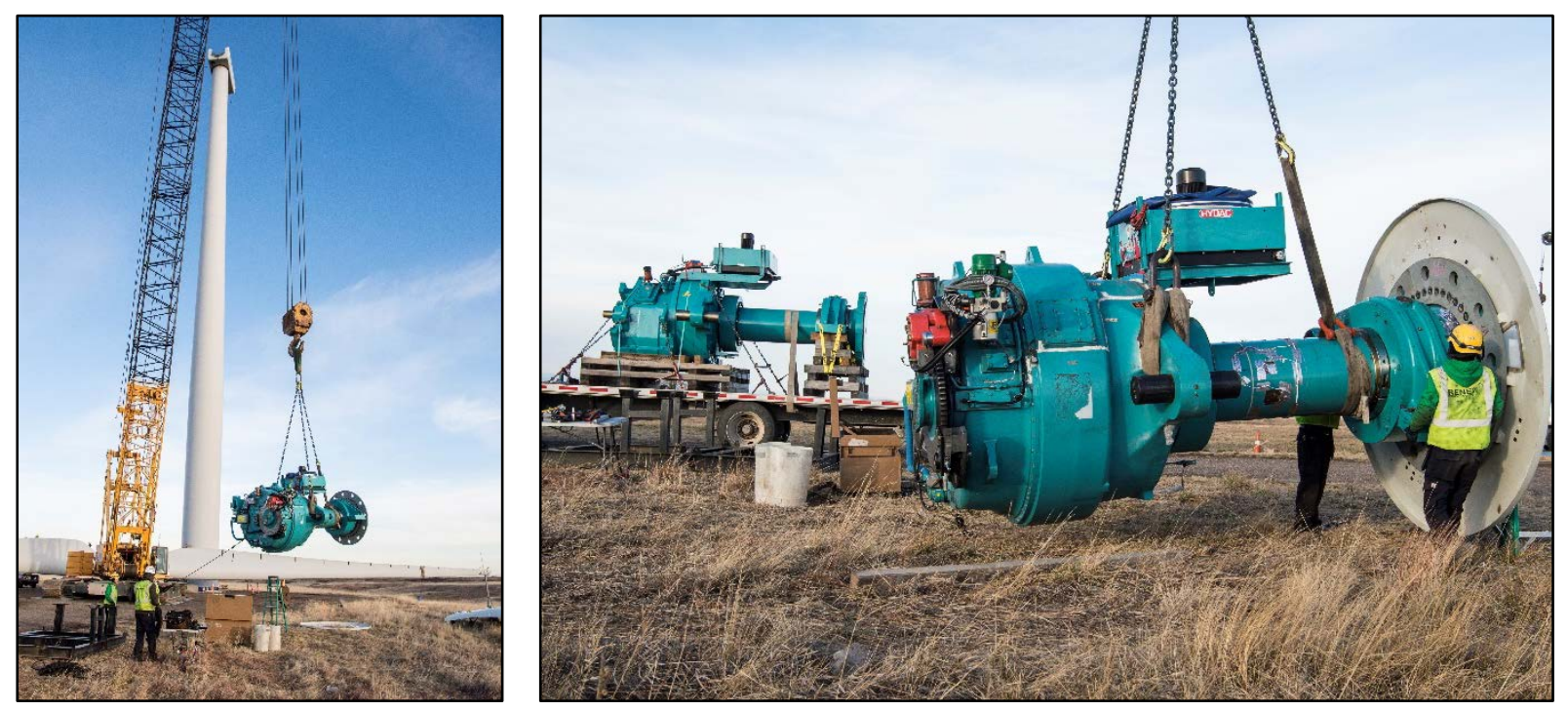

Figure 1. GETS gearbox removal (left) and swap (right) Photos by Dennis Schroeder, NREL 49407 and 49418

The GETS gearbox is a model number 7GA87E2 (serial number EE0809404). It has a ratio of 78.472 and rated input power, torque, and speed of 1.667 MW, 870 kilonewton meter $(\mathrm{kNm})$, and $18.3 \mathrm{rpm}$, respectively. It was filled with Castrol Optigear A320 oil for its entire time in service. This gearbox has three stages comprised of a compound planetary system and a highspeed stage with helical gearing throughout. Schematic diagrams of the gearbox are shown in Figure 2 [21]. 


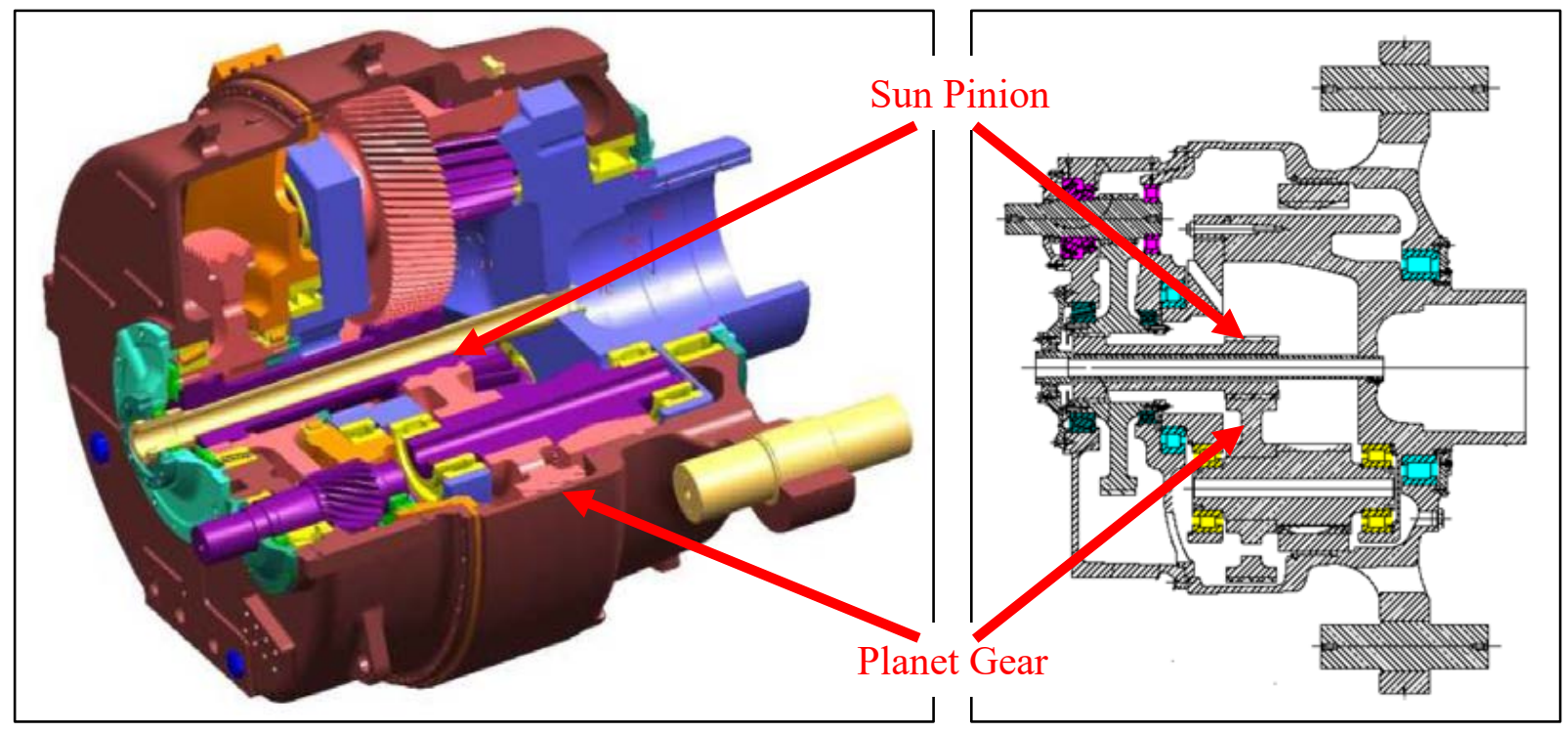

Figure 2. Schematic (left) and cutaway view (right) of the 7GA87 gearbox [21] Illustration by Anthony Giammarise, General Electric Transportation

Based on the rated properties of the gearbox and the characteristics of a compound planetary system, the basic gear technical data for the sun pinion and mating planet gear is provided in Table 1 along with properties of the lubricant [22].

Table 1. Gearbox and Lubricant Technical Data

\begin{tabular}{lcccc}
\hline Parameter & Symbol & Sun Pinion & Planet Gears & Unit \\
\hline Rotation speed & $n$ & 254.2 & 54.1 & $\mathrm{rpm}$ \\
Transmitted power & $P$ & 1.667 & 1.667 & $\mathrm{MW}$ \\
Nominal torque & $T$ & 62.6 & 294.5 & $\mathrm{kNm}$ \\
Number of teeth & $z$ & 27 & 88 & - \\
Mean coefficient of friction & $\mu_{m}$ & & 0.055 & - \\
Kinematic viscosity at $100^{\circ} \mathrm{C}$ & $v_{100}$ & & 33 & $\mathrm{~mm}^{2} / \mathrm{s}$ \\
Kinematic viscosity at $40^{\circ} \mathrm{C}$ & $v_{40}$ & & 330 & $\mathrm{~mm}^{2} / \mathrm{s}$ \\
Density of lubricant at $15^{\circ} \mathrm{C}$ & $\rho_{15}$ & & 870 & $\mathrm{~kg} / \mathrm{m}^{3}$ \\
\hline
\end{tabular}




\section{Gearbox Condition}

Several physical inspections of the original gearbox, gears, and bearings were made while the gearbox was installed in the turbine, after it was removed, and after it was disassembled as described in the remainder of this section.

\subsection{Inspections}

The first physical inspection of the gearing was conducted by GE personnel in November 2012 during an uptower borescope inspection. Although the focus of the inspection was to assess the condition of most of the bearings in the gearbox, several photos were taken of the gearing. At the time, and within the limits of borescope access, there was no sign of significant damage or bearing failure; no spalling, debris, or over-rolled indents; no significant scratching or abrasion of gears that would indicate appreciable bearing deterioration; and only minor marks and scratches observed on the cage of one of the bearings supporting the high-speed pinion [23]. Example borescope photos of the sun pinion are shown in Figure 3.
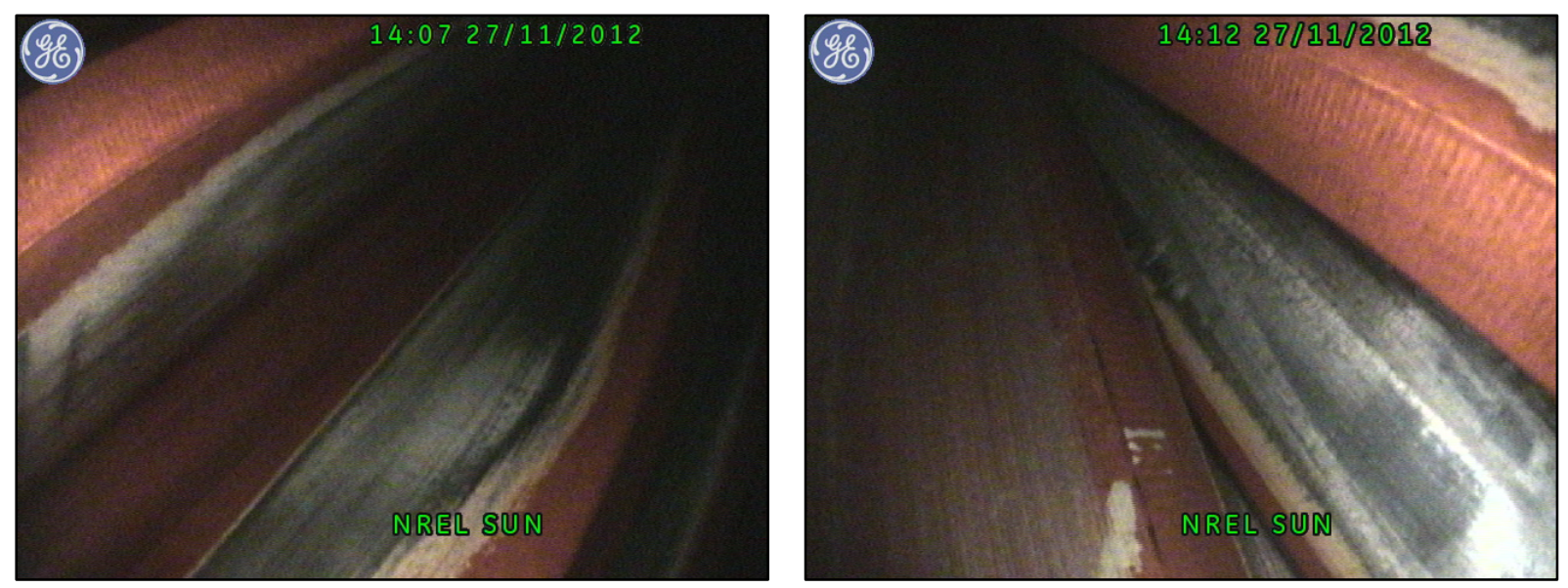

Figure 3. Typical condition of the sun pinion teeth in 2012 Photos from John T. Murphy, GE Renewables

A second borescope inspection was conducted by Romax Technology personnel in November 2015. In this case, half of the sun pinion teeth and all of the mating planet gear teeth were inspected along with some of the other gearing and bearings. Some damage was documented on the sun pinion teeth that were inspected. The rotor- and generator-side flanks of several teeth showed hard contact lines. One tooth had isolated abrasive wear marks while another had an area of isolated micropitting. The roots of several teeth showed evidence of the onset of micropitting at the start of the active profile as shown in Figure 4. Only normal wear was noted on the planet gears and any of the accessible bearings [24]. Hereafter, the primary item of interest on this gearbox became the micropitting on the sun pinion. 


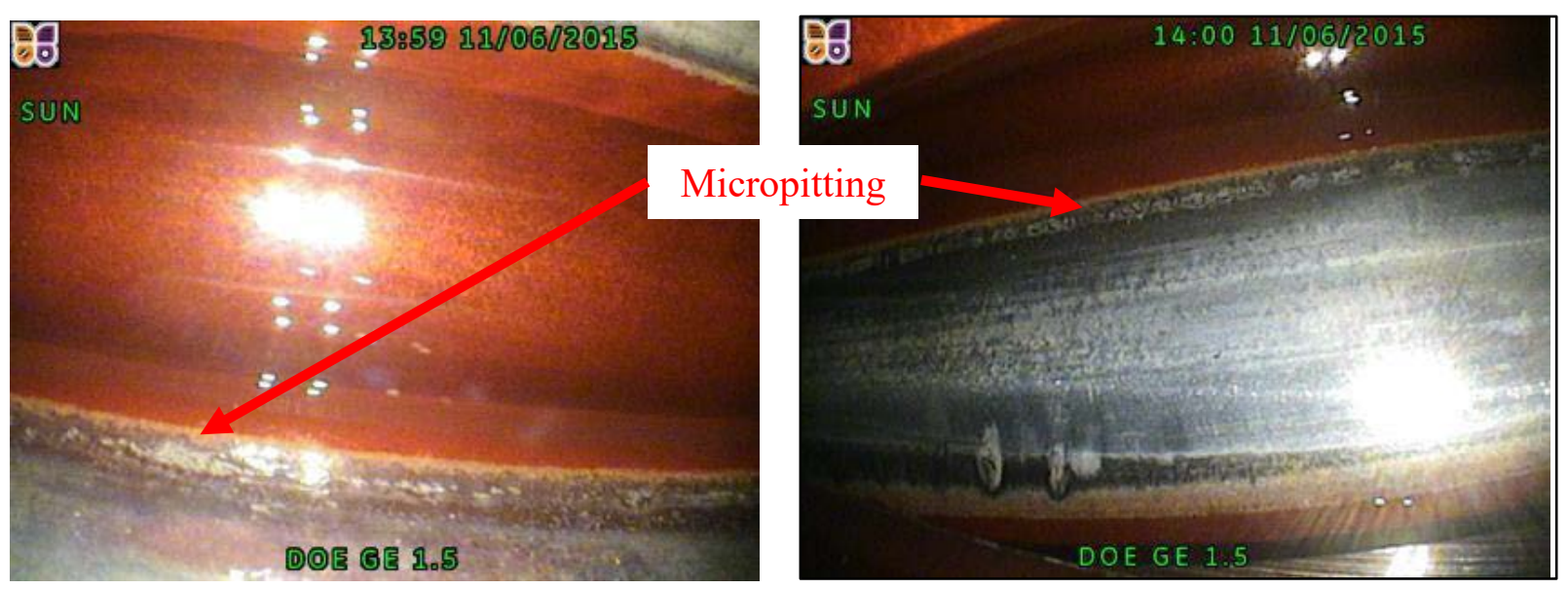

Figure 4. Micropitting of the sun pinion teeth in 2015

Photos by Jesse Graeter, Onyx InSight, NREL 61223 and 61224

GE also performed the last semiannual maintenance inspection of the gearbox in September 2017. During the inspection, it was noted that there was excess black sludge and sediment in the gearbox oil filter sediment collector [25]. Further oil analysis was recommended and completed by SGS Laboratories in November 2017. Abnormal test results were present. The particle count was higher than desirable and/or acceptable. Most of the particulate in the filter consisted of copper alloy and steel, with $82.9 \%$ of the particles less than 4 microns $(\mu \mathrm{m})$ in equivalent diameter. The zinc dialkyldithiophosphate antioxidant for the oil itself was less than $40 \%$ of current new oil reference, and the water contamination was in the warning range [26].

After the gearbox was removed from the turbine in December 2017, a third borescope inspection was performed in April 2018 by personnel from Wind Driven. By this time, it was clear that the sun pinion was the most heavily damaged component. Micropitting, occasional abrasion, and corrosion were observed on the sun pinion teeth. Micropitting was found in the roots of all teeth, an example of which is shown in Figure 5 [27].
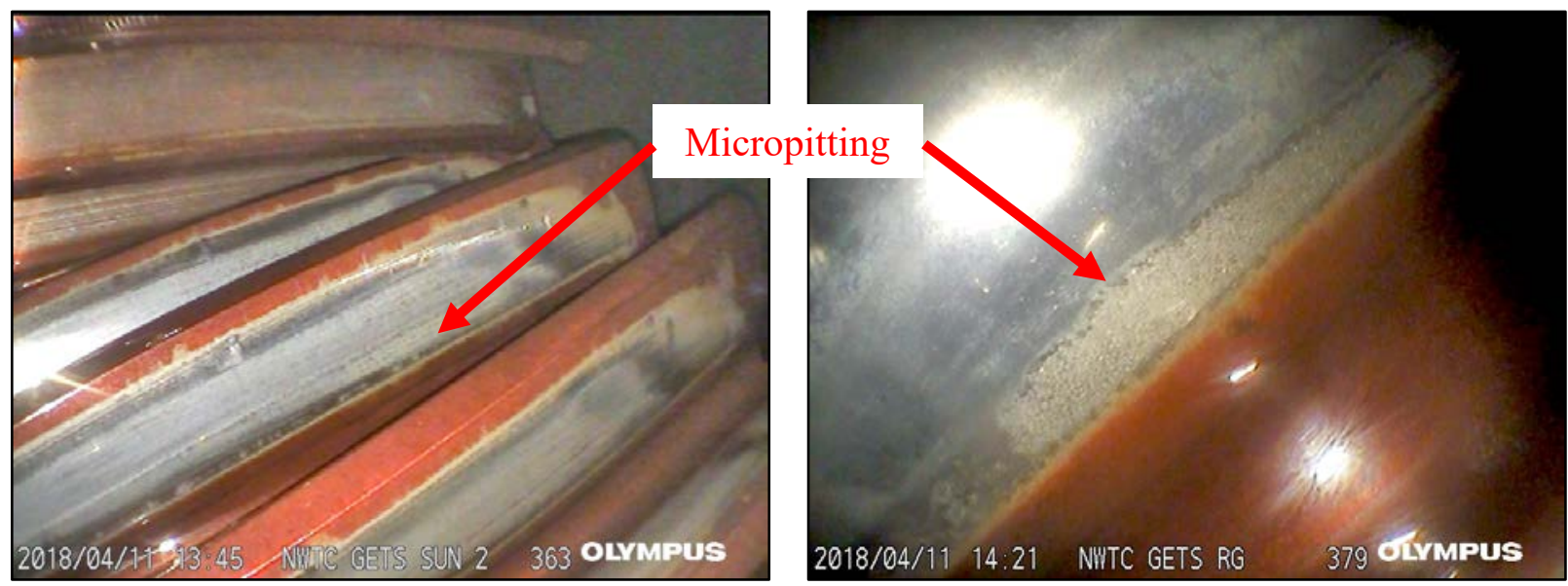

Figure 5. Micropitting of the sun pinion teeth in 2018

Photos by Scott Eatherton, Wind Driven, NREL 61193 and 61194 


\subsection{Disassembly}

The gearbox was trucked to Renew Energy Maintenance facilities and disassembled in May 2019 as shown in Figure 6. During the disassembly process, particular attention was paid to the condition of the sun pinion (part number 84E901974 P2, revision D, serial number 0808010) and the mating planet gears (part number 84E901975 P3, revision E, serial numbers 0808002, 0808095, and 0808140). Additional technical details of each of these helical gears are listed in Table 1. During the disassembly, the condition of all gears was examined. In general, the gears showed no significant damage - no major foreign object damage, tooth chips, or tooth cracks were found.
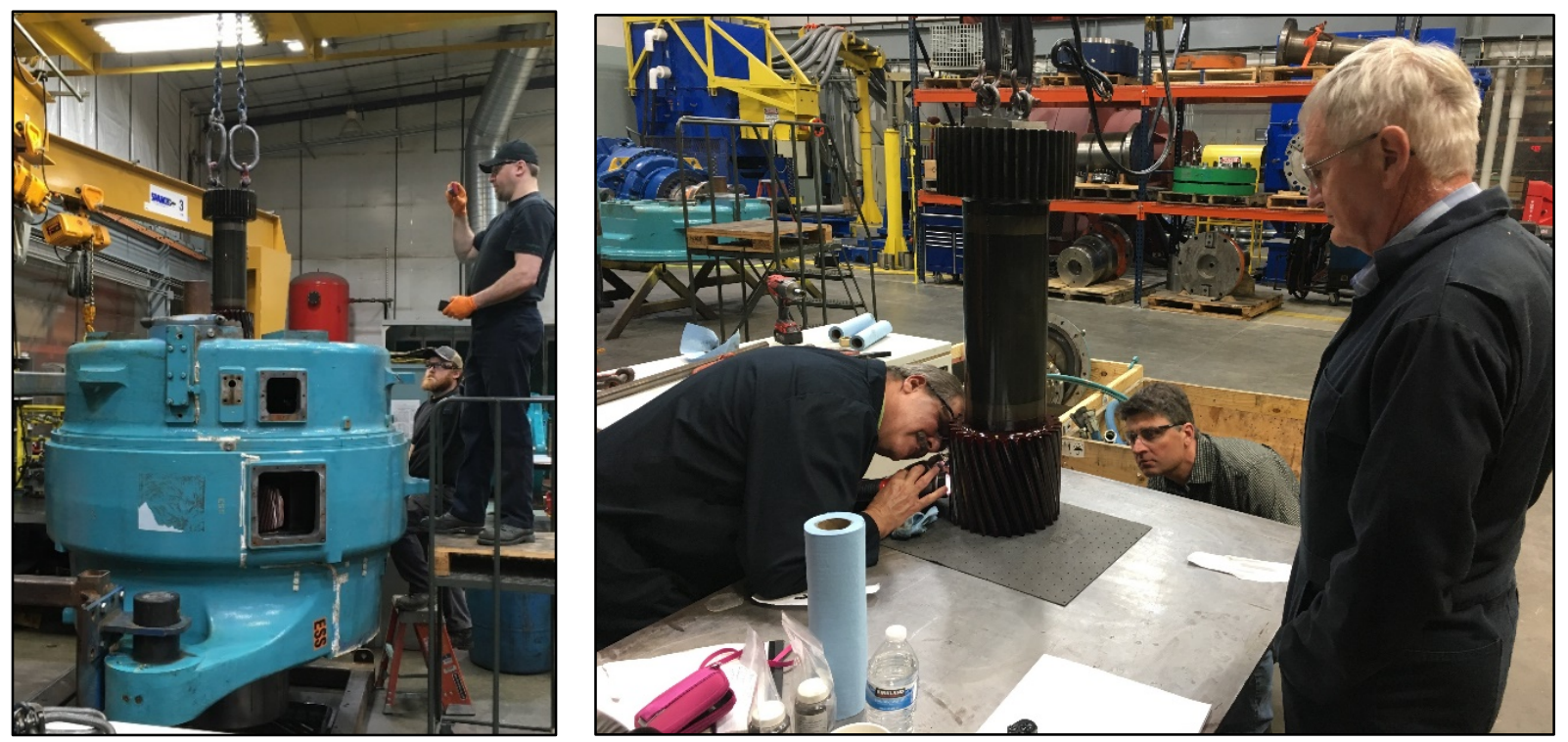

Figure 6. Gearbox disassembly (left) and sun pinion inspection (right) Photos by Jonathan Keller, NREL 61027 and 61028

\subsection{Metrology and Profilometry}

After disassembly, in June 2019, all of the gearing was shipped to Machinists Incorporated (formerly The Gear Works) for cleaning, inspection for accuracy, and measurement of the timing of the planetary pinions and gears. Inspection charts for the sun pinion are included in the Appendix. The inspections showed that the gear teeth profiles were still accurate and no significant wear was found. One localized spot of damage with a micropitting halo surrounding it was found on the drive-side flank of a tooth of the sun pinion, hereafter identified as Tooth 1. It likely originated from a spot of grind temper or corrosion and was measured in the lead profile chart in Figure A-2 in the Appendix.

The gearing was shipped to REM Surface Engineering for profilometry measurements in July 2019. Additional photographic evidence of the drive-side root micropitting and localized damage on the sun pinion described above is shown in Figure 7. In the figure, the patches of micropitting had not yet coalesced across the tooth contact zone. This is considered early-onset micropitting. Roughness measurements were acquired away from the gear contact zone and away from any damage or micropitting on the gear teeth flanks of the sun pinion and mating planets to assess the as-manufactured surface roughness of the gears. The roughness measurement, $\mathrm{Ra}$, was $0.22 \mu \mathrm{m}$ 
on the sun pinion and $0.55 \mu \mathrm{m}$ on the mating planets, yielding a composite roughness of approximately $0.4 \mu \mathrm{m}$. The localized corrosion spot with micropitting on Tooth 1 was measured to be approximately 3-millimeters $(\mathrm{mm})$ long and $2.5-\mathrm{mm}$ wide. The damage in the center of the halo was approximately $3.4 \mu \mathrm{m}$, or 1.4 ten-thousandth of an inch, deep, Rz. It was considered to be the most severe damage on the sun pinion.
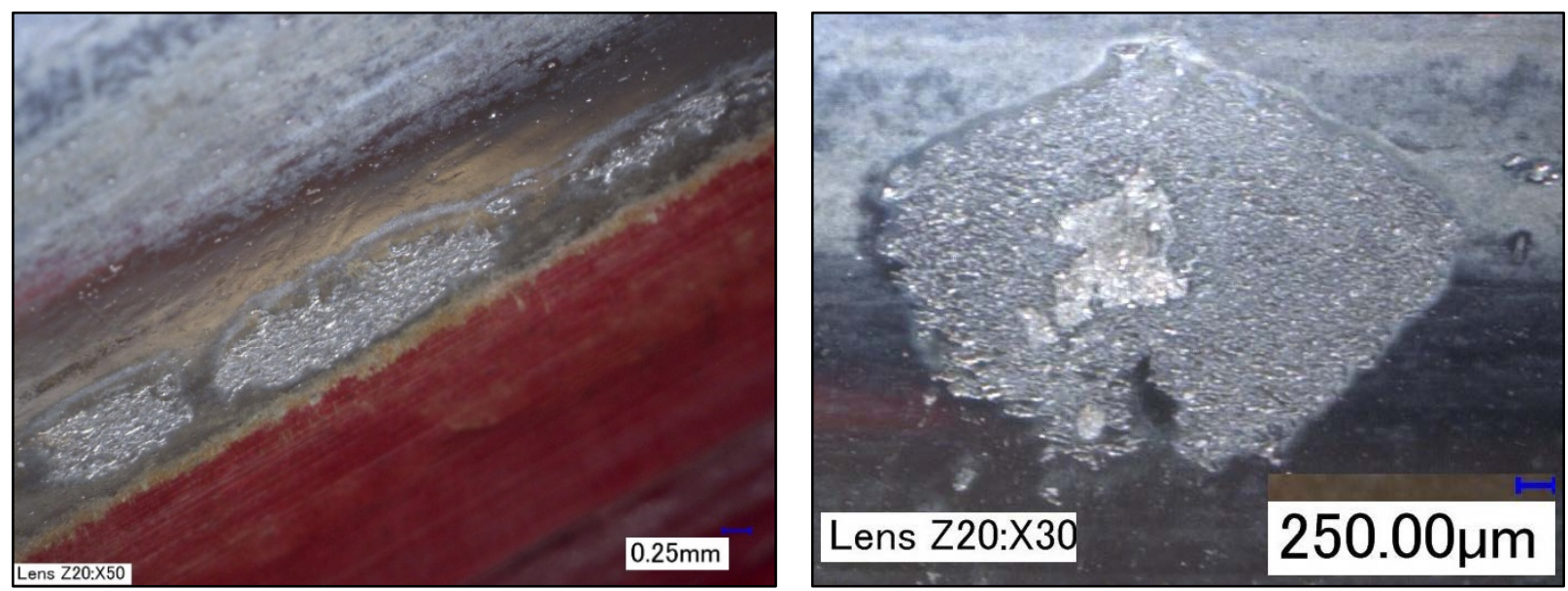

Figure 7. Sun pinion root micropitting (left) and localized corrosion spot with micropitting halo (right)

Photos from REM Surface Engineering, NREL 61192 and 61191

Finally, after the profilometry measurements were completed, all of the gearing was refurbished by an isotropic superfinishing process [28]. All tooth-flank surface damage was repaired by removing approximately $3.5 \mu \mathrm{m}$ from each flank of all of the gearing. Before-and-after isotropic superfinishing photographs of the sun pinion are shown in Figure 8.
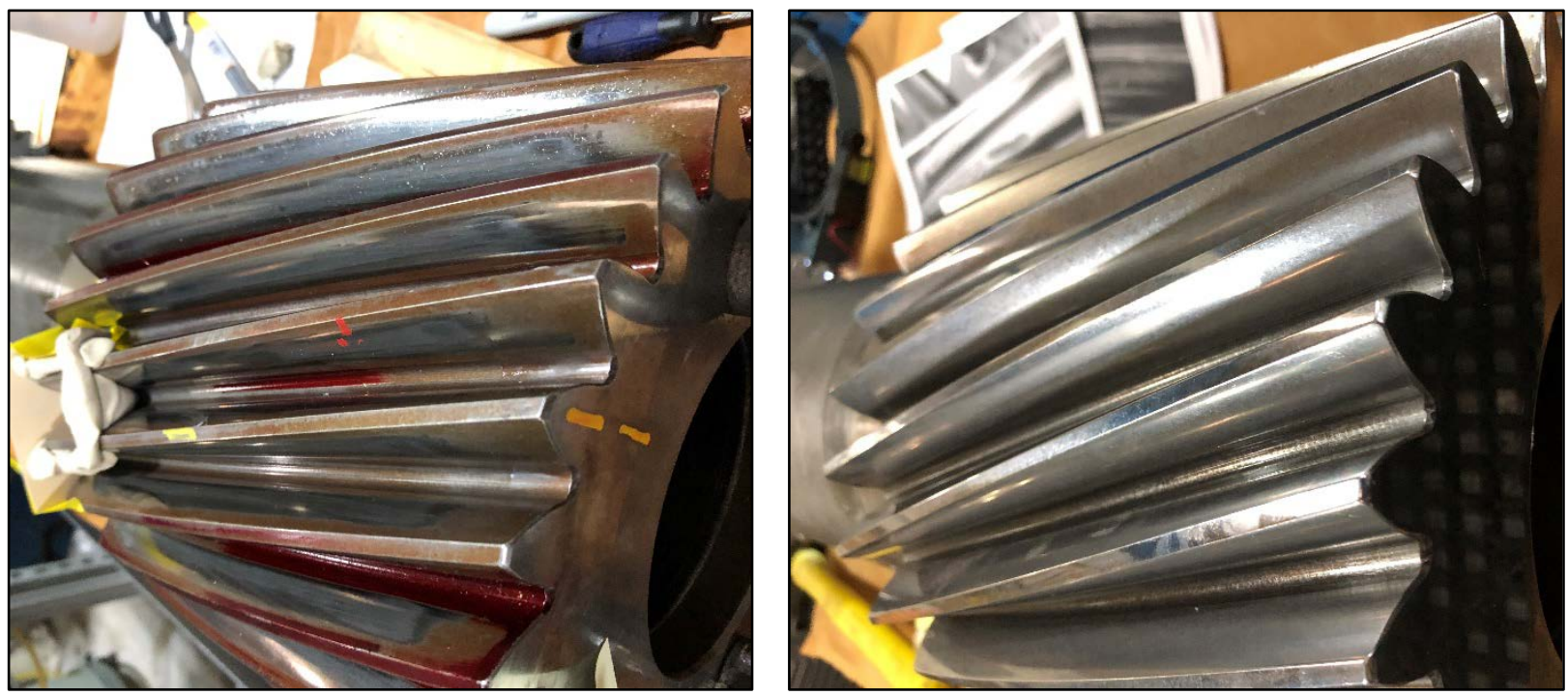

Figure 8. Sun pinion before (left) and after (right) isotropic superfinishing Photos from REM Surface Engineering, NREL 61190 and 61189 


\section{Summary}

Micropitting is an asperity-level fatigue phenomenon that occurs in hertzian contacts in both gears and rolling-element bearings that operate in mixed- or micro-elastohydrodynamic lubrication regimes. It manifests itself in many different ways in gear teeth, ranging from surface microcracking generating small debris particles, to a significant loss of material, and to degradation of gear-tooth accuracy. In some cases, it can be the primary failure mode of a gearbox. Despite much research by many investigators, micropitting remains complex, unpredictable, difficult to control, and a problem in wind turbine gearboxes.

As the first step in a new research effort to investigate micropitting, this report documents and describes the micropitting damage observed in a GETS wind turbine gearbox. The gearbox was installed in a GE 1.5 SLE wind turbine for slightly more than 8.5 years and accumulated over 14,000 hours of operational time. Routine borescope inspections first noted the formation of micropitting on the sun pinion after 6.5 years of operation. After the gearbox was removed from the turbine, it was disassembled and inspected. Evidence of early-onset micropitting was documented on the drive side of every tooth of the sun pinion. The information described in this report will be used in an upcoming case study of the ISO/TS 6336-22 micropitting safety factor method when applied to several gear sets and applications that have experienced micropitting in the field.

Although one spot of localized damage on the sun pinion was measured to be approximately 3$\mathrm{mm}$ long, 2.5-mm wide, and 3.4- $\mu \mathrm{m}$ deep, the sun pinion and all other gearing were successfully refurbished with the removal of approximately $3.5 \mu \mathrm{m}$ from each tooth flank. Since the gears were successfully refurbished with the REM Surface Engineering isotropic superfinishing process, the gearing will be installed in another GETS gearbox during an uptower repair at a commercial wind plant in the future. This gearbox will be monitored for any indications of micropitting or other damage through vibration, oil sensors, oil samples, and borescope inspections, and the data will be accumulated for future analysis and reporting. 


\section{References}

1. Wiser, R. and M. Bolinger. 2019. 2018 Wind Technologies Market Report (Technical Report). DOE/GO-102019-5191. U.S. Department of Energy: Washington, D.C, 2019. doi: $\underline{10.2172 / 1559881 .}$.

2. Kotzalas, M. N. and G. L. Doll. 2010. "Tribological Advancements for Reliable Wind Turbine Performance." Philosophical Transactions of The Royal Society, 368: 4829-4850. doi: 10.1098/rsta.2010.0194.

3. Wiser, R., M. Bolinger, and E. Lantz. 2019. "Assessing Wind Power Operating Costs in the United States: Results from a Survey of Wind Industry Experts." Renewable Energy Focus, 30: 46-57. doi: 10.1016/j.ref.2019.05.003.

4. Greco, A., S. Sheng, J. Keller, and A. Erdemir. 2013. "Material Wear and Fatigue in Wind Turbine Systems." Wear, 302: 1583-1591. doi: 10.1016/j.wear.2013.01.060.

5. Sheng, S. 2017. Wind Turbine Gearbox Reliability Database, Condition Monitoring, and O\&M Research Update (Presentation). NREL/PR-5000-68347. National Renewable Energy Laboratory: Golden, CO. https://www.nrel.gov/docs/fy17osti/68347.pdf.

6. American Gear Manufacturers Association. 2003. "Effect of Lubrication on Gear Surface Distress." AGMA 925-A03.

7. Errichello, R. L. 2011. "Morphology of Micropitting." AGMA Technical Paper 11FTM17, AGMA Fall Technical Meeting.

8. Errichello, R. L. 2005. "Micropitting of Gear Teeth-A Review of the Literature, Description of Morphology, Mechanism, and Significance and Guidelines for Prevention."

9. Clarke, A., H. P Evans, and R. W. Snidle. 2015. "Understanding Micropitting in Gears." Proceedings of the Institution of Mechanical Engineers Part C: Journal of Mechanical Engineering Science, 230: 1276-1289. doi: 10.1177/0954406215606934.

10. ISO Technical Committee 60. 2018. "Calculation of load capacity of spur and helical gearsPart 22: Calculation of micropitting load capacity.” ISO/TS 6336-22:2018.

11. Errichello, R. L. 2016. "Critique of ISO 15144-1 Method to Predict the Risk of Micropitting.” Gear Technology, 33: 10-16.

12. Guo, Y., S. Lambert, R. Wallen, R. Errichello, and J. Keller. 2016. "Theoretical and experimental study on gear-coupling contact and loads considering misalignment, torque, and friction influences." Mechanism and Machine Theory, 98: 242-262. doi: 10.1016/j.mechmachtheory.2015.11.015.

13. Keller, J., Y. Guo, Z. Zhang, and D. Lucas. 2018. "Comparison of planetary bearing loadsharing characteristics in wind turbine gearboxes." Wind Energy Science, 3: 947-960, doi: 10.5194/wes-3-947-2018. 
14. Keller, J., B. Gould, and A. Greco. 2017. Investigation of Bearing Axial Cracking: Benchtop and Full-Scale Test Results (Technical Report). NREL/TP-5000-67523. National Renewable Energy Laboratory: Golden, CO. http://www.nrel.gov/docs/fy17osti/67523.pdf.

15. Keller, J. 2018. Investigating Main and High-Speed Shaft Bearing Reliability Through Uptower Testing (Presentation). NREL/PR-5000-70958. National Renewable Energy Laboratory: Golden, CO. http://www.nrel.gov/docs/fy18osti/70958.pdf.

16. S. Sheng. 2010. Wind Turbine Micropitting Workshop: A Recap (Technical Report). NREL/TP-500- 46572. National Renewable Energy Laboratory: Golden, CO. http://www.nrel.gov/docs/fy10osti/46572.pdf.

17. Errichello, R., J. Keller, S. Sheng, and A. Greco. 2012. Wind Turbine Tribology Seminar-A Recap (Technical Report). DOE/GO-102011-3496. National Renewable Energy Laboratory: Golden, CO. http://www.nrel.gov/docs/fy120sti/53754.pdf.

18. Keller, J., S. Sheng, J. Cotrell, and A. Greco. 2016. Wind Turbine Drivetrain Reliability Collaborative Workshop: A Recap (Technical Report). DOE/GO-102016-4878. National Renewable Energy Laboratory: Golden, CO. http://www.nrel.gov/docs/fy16osti/66593.pdf.

19. Santos, R., and J. van Dam. 2015. Mechanical Loads Test Report for the U.S. Department of Energy 1.5-Megawatt Wind Turbine (Technical Report). NREL/TP-5000-63679. National Renewable Energy Laboratory: Golden, CO. http://www.nrel.gov/docs/fy15osti/63679.pdf.

20. Keller, J, Y. Guo, and L. Sethuraman. 2019. Uptower Investigation of Main and High-SpeedShaft Bearing Reliability (Technical Report). NREL/TP-5000-71529. National Renewable Energy Laboratory: Golden, CO. http://www.nrel.gov/docs/fy19osti/71529.pdf.

21. Giammarise, A. and M. Sirak. 2009. "Challenges of Large MMW Gearboxes in Wind Turbine Applications.” Sandia Wind Turbine Reliability Workshop: Albuquerque, NM. https://windpower.sandia.gov/2009Reliability/PDFs/Day2-03-AnthonyGiammarise.pdf.

22. Castrol. 2009. Product Data Castrol Optigear Synthetic A. https://msdspds.castrol.com/bpglis/FusionPDS.nsf/Files/AD6A642C79F8C79D80257796003 012DF/\$File/450763 US en.pdf.

23. Murphy, J. T. 2012. NREL 1.5 SLE GETS Gearbox Borescope Inspection (unpublished inspection report).

24. Graeter, J. 2015. Main Gearbox Inspection for the National Renewable Energy Laboratory (unpublished inspection report).

25. Andrade, A. 2017. Semiannual Maintenance Proof (unpublished maintenance report).

26. Villalba, M. L. 2017. Certificate of Analysis (unpublished).

27. Eatherton, S. 2018. Borescope Inspection Report: NTWC GE Transportation Gearbox (unpublished inspection report). 
28. Michaud, M., G. J. Sroka, and R. E. Benson. 2010. "A Novel Approach to the Refurbishment of Wind Turbine Gears.” AGMA Technical Paper 10FTM03, AGMA Fall Technical Meeting. 


\section{Appendix}

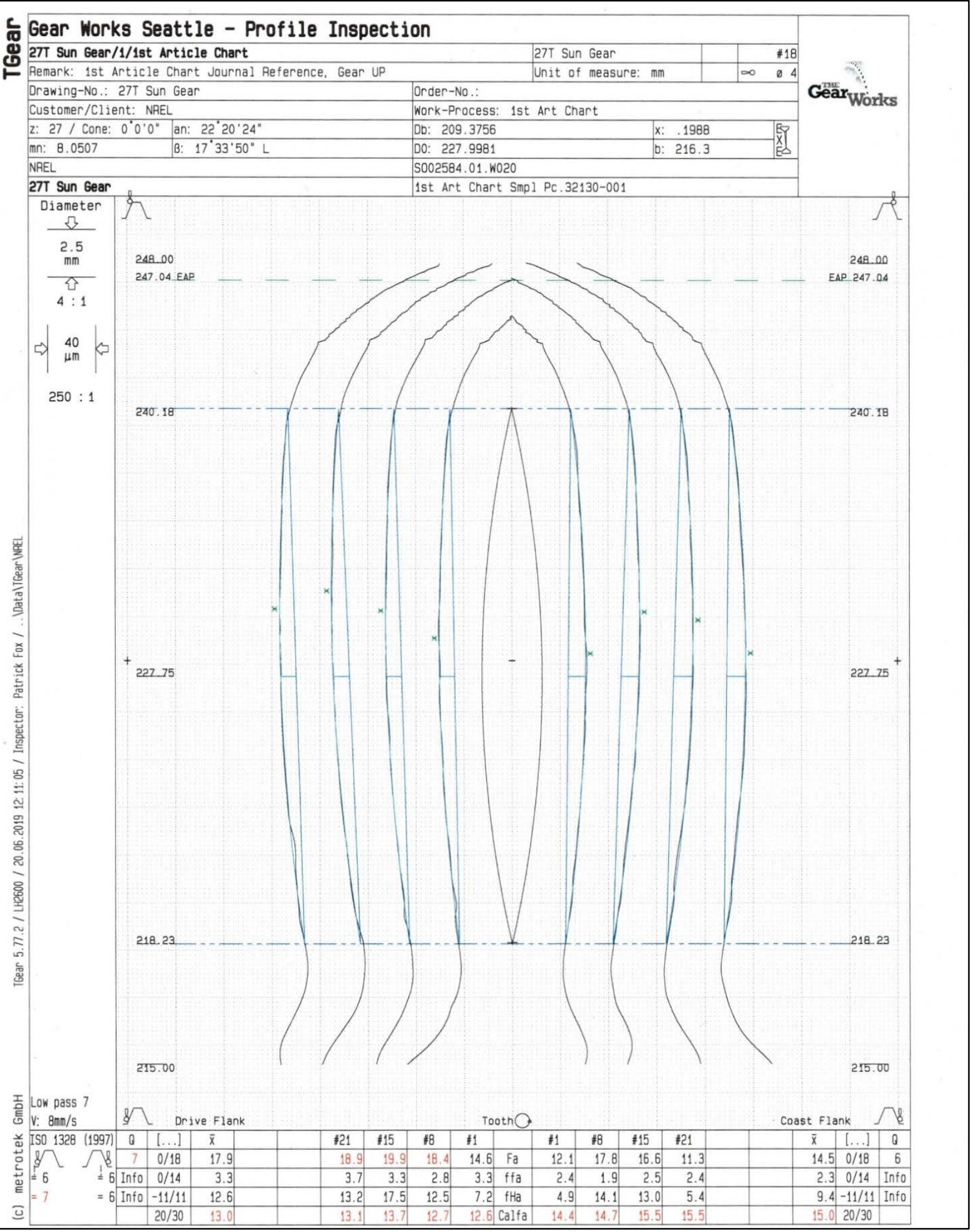

Figure A-1. Sun pinion profile inspection (250:1) 


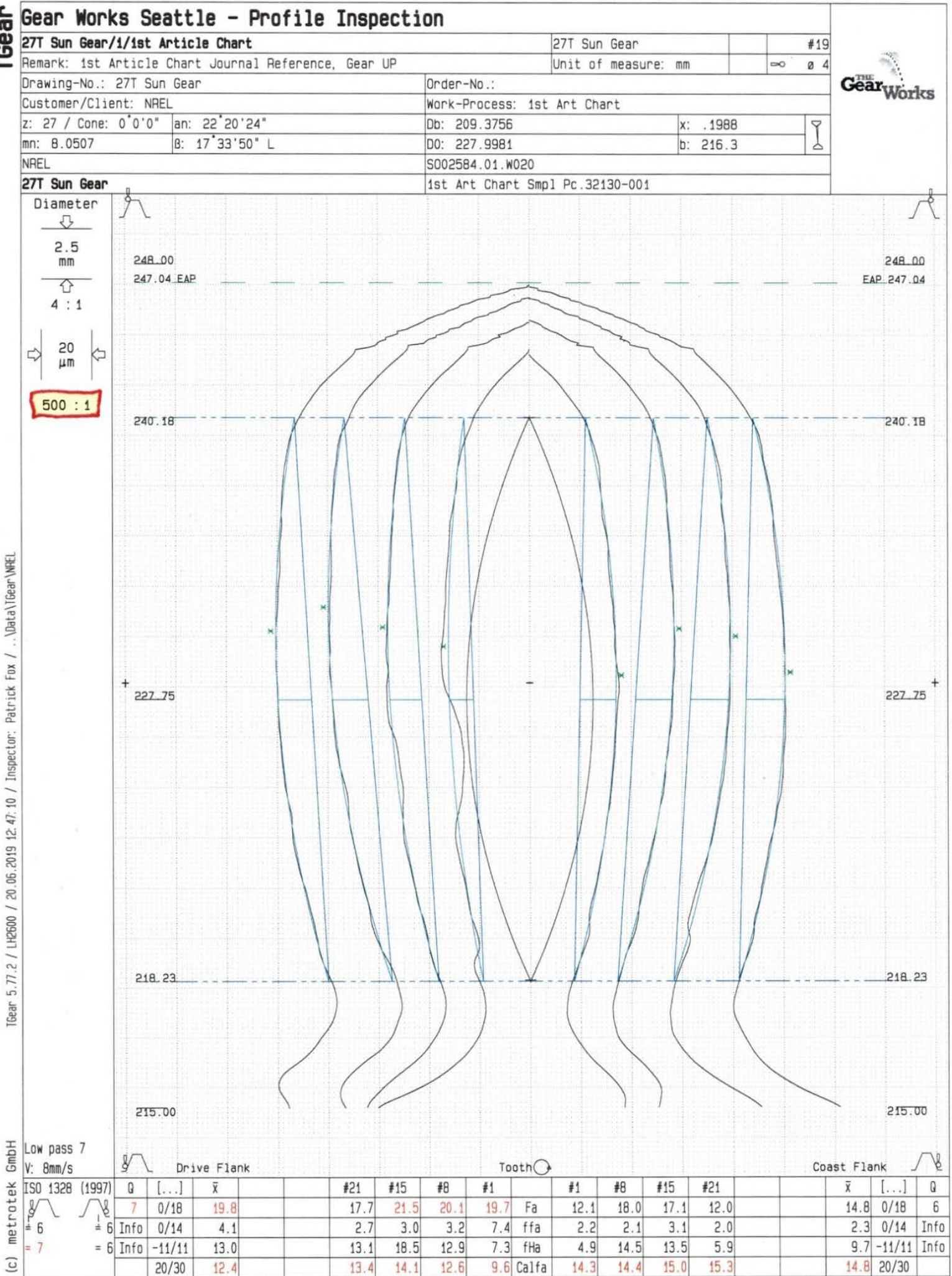

Figure A-2. Sun pinion profile inspection (500:1) 


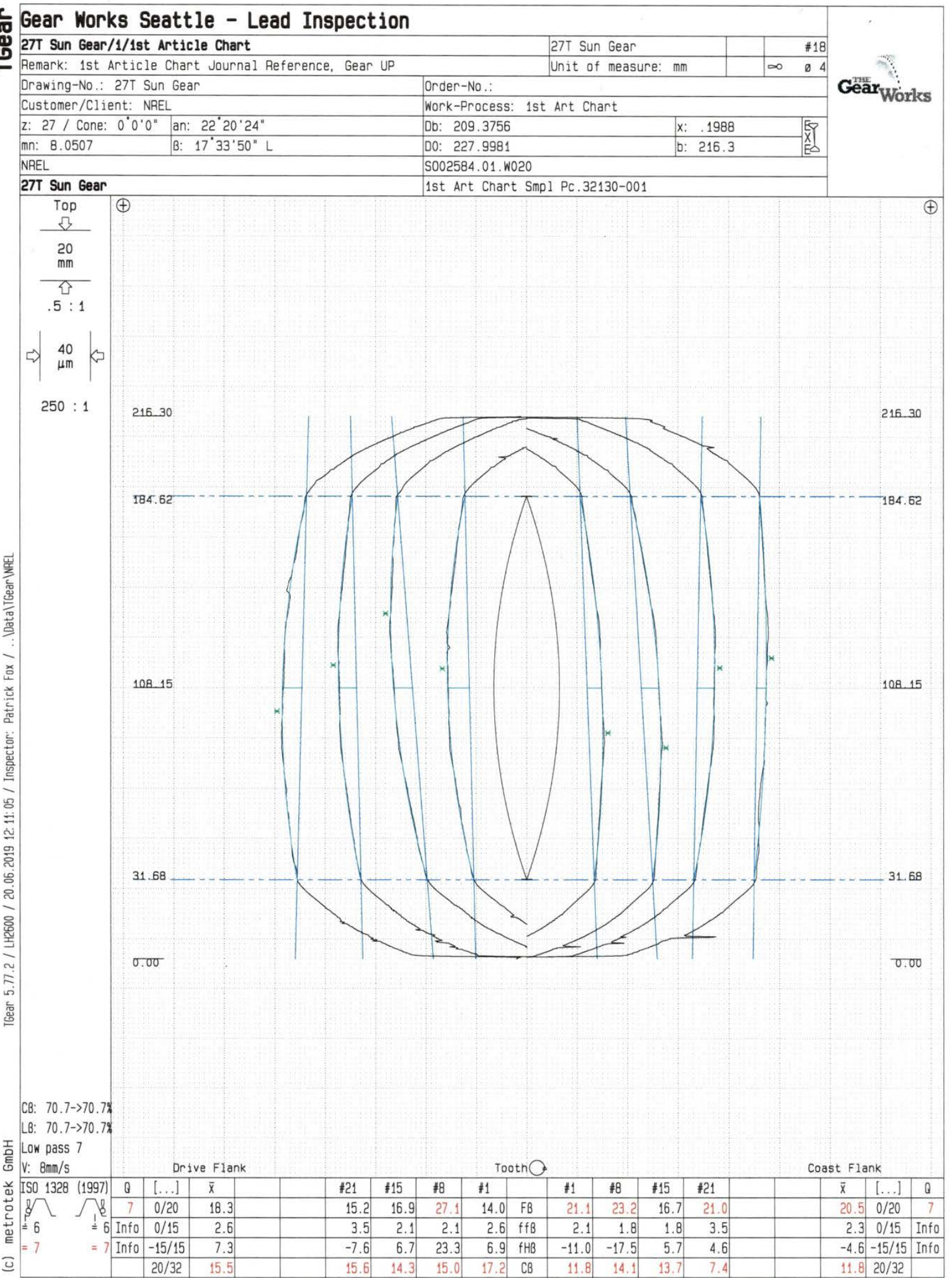

Figure A-3. Sun pinion lead inspection (250:1) 
Gear Works Seattle - Pitch and Runout Test

\$ $27 T$ Sun Gear/1/1st Article Chart

- Remark: 1st Article Chart Journal Reference, Gear UP. Drawing-No.: 27T Sun Gear

Customer/Client: NREL

Z: $27 /$ Cone: $0^{\circ} 0^{\circ} 0^{\prime \prime}$ an: $22^{\circ} 20^{\circ} 24^{\circ}$

\begin{tabular}{l|l|l}
\hline In: 8.0507 & B: $17^{\circ} 33^{\prime} 50^{\prime \prime} \mathrm{L}$ \\
\hline NREL &
\end{tabular}

NREL

27T Sun Gear
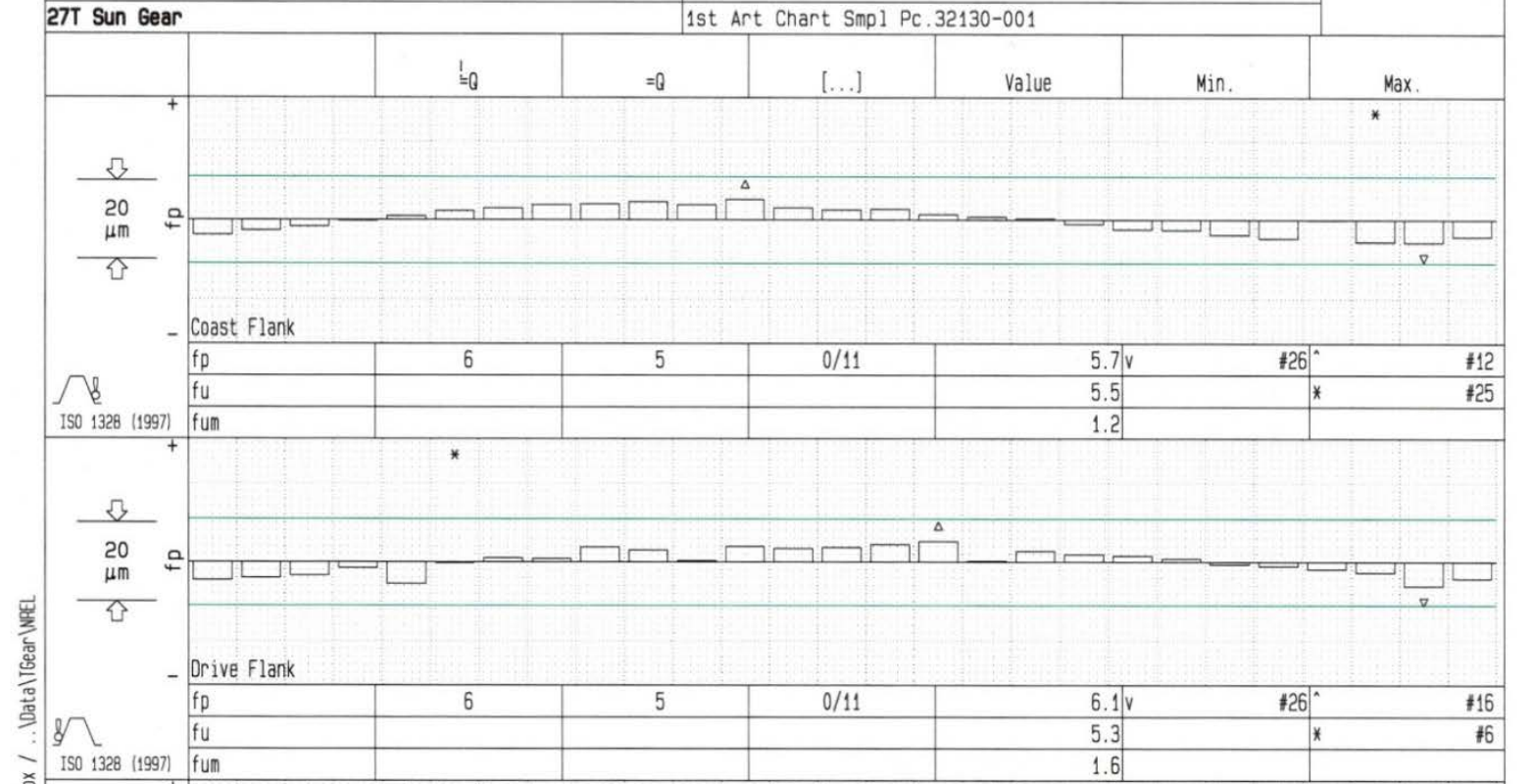

중
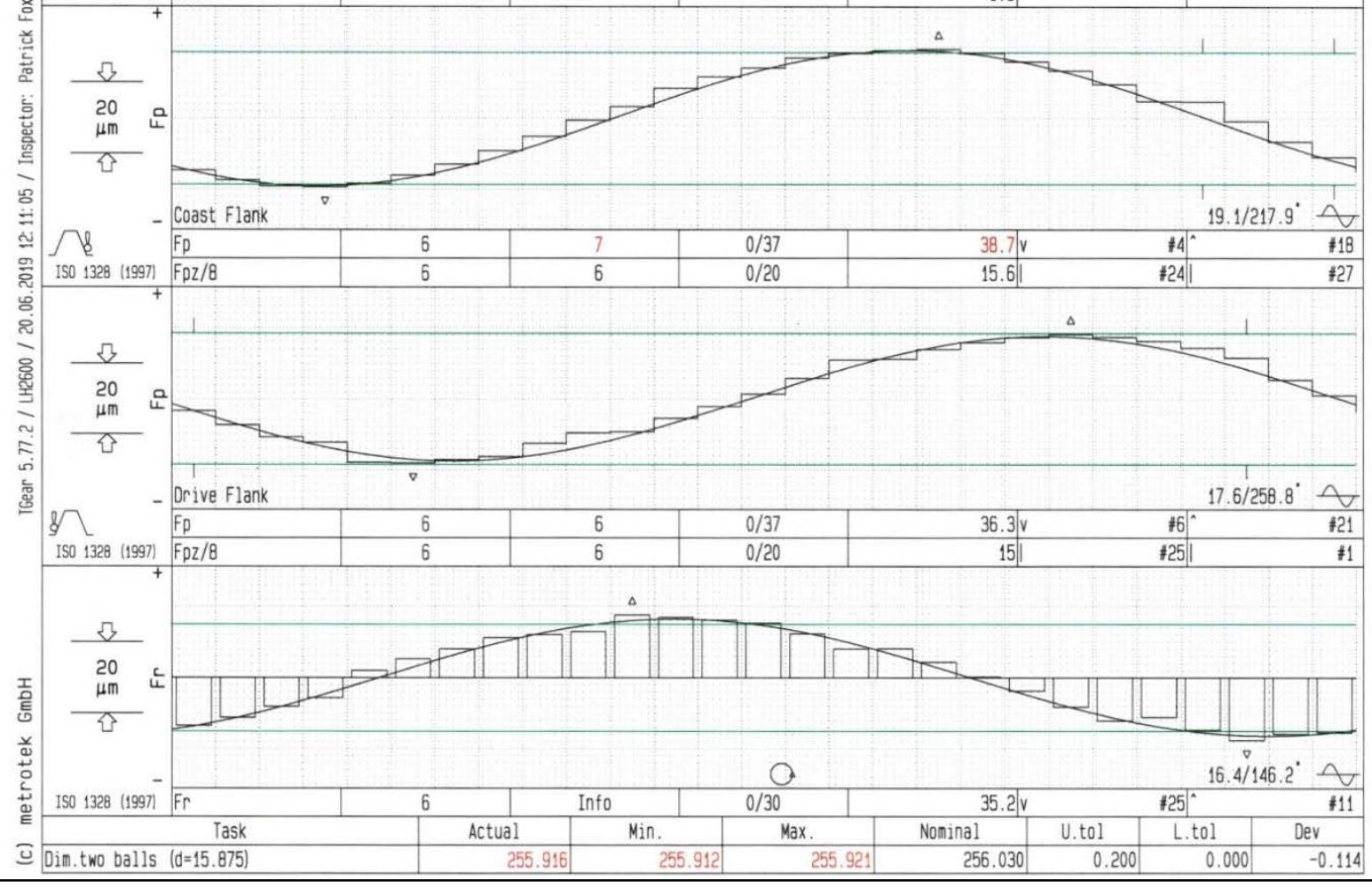

Figure A-4. Sun pinion pitch and runout test

This report is available at no cost from the National Renewable Energy Laboratory at www.nrel.gov/publications. 